\title{
Deeply cooled and temperature controlled microjets: Liquid ammonia solutions released into vacuum for analysis by photoelectron spectroscopy
}

Cite as: Rev. Sci. Instrum. 91, 043101 (2020); https://doi.org/10.1063/1.5141359

Submitted: 04 December 2019 . Accepted: 17 March 2020. Published Online: 09 April 2020

Tillmann Buttersack (D), Philip E. Mason, Pavel Jungwirth (D), H. Christian Schewe, Bernd Winter, Robert Seidel (D), Ryan S. McMullen (D), and Stephen E. Bradforth (D)

\section{COLLECTIONS}

This paper was selected as Featured
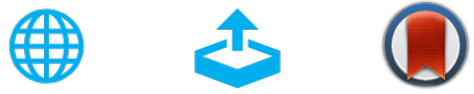

\section{ARTICLES YOU MAY BE INTERESTED IN}

High resolution time- and angle-resolved photoemission spectroscopy with $11 \mathrm{eV}$ laser pulses

Review of Scientific Instruments 91, 043102 (2020); https://doi.org/10.1063/1.5139556

Temperature controlled microjets for liquid ammonia solutions

Scilight 2020, 151105 (2020); https://doi.org/10.1063/10.0001131

Modeling the fringe field of permanent magnet multipoles using numerical simulations Review of Scientific Instruments 91, 043305 (2020); https://doi.org/10.1063/5.0008335

\section{Lock-in Amplifiers up to $600 \mathrm{MHz}$}
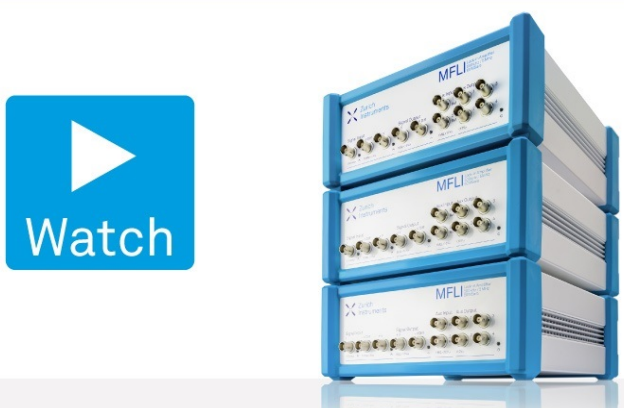


\title{
Deeply cooled and temperature controlled microjets: Liquid ammonia solutions released into vacuum for analysis by photoelectron spectroscopy
}

\author{
Cite as: Rev. Sci. Instrum. 91, 043101 (2020); doi: 10.1063/1.5141359 \\ Submitted: 4 December 2019 • Accepted: 17 March 2020 • \\ Published Online: 9 April 2020
}

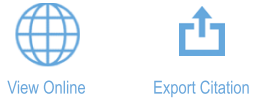

H. Christian Schewe, ${ }^{3}$ Bernd Winter,

Tillmann Buttersack, ${ }^{1,2, a)}$ (D) Philip E. Mason, ${ }^{7}$ Pavel Jungwirth, Robert Seidel, ${ }^{4}$ (D) Ryan S. McMullen, ${ }^{2}$ (D) and Stephen E. Bradforth

\begin{abstract}
AFFILIATIONS
${ }^{1}$ Institute of Organic Chemistry and Biochemistry, Czech Academy of Sciences, Flemingovo nam. 2, 16610 Prague 6, Czech Republic

2Department of Chemistry, University of Southern California, Los Angeles, California 90089-0482, USA

${ }^{3}$ Fritz-Haber-Institut der Max-Planck-Gesellschaft, Molekülphysik, Faradayweg 4-6, 14195 Berlin, Germany

${ }^{4} \mathrm{Helmholtz-Zentrum} \mathrm{Berlin} \mathrm{für} \mathrm{Materialien} \mathrm{und} \mathrm{Energie,} \mathrm{Albert-Einstein-Straße} \mathrm{15,} 12489$ Berlin, Germany and Department of Chemistry, Humboldt-Universität zu Berlin, Brook-Taylor-Straße 2, 12489 Berlin, Germany
\end{abstract}

${ }^{a)}$ Author to whom correspondence should be addressed: buttersa@usc.edu

\begin{abstract}
A versatile, temperature controlled apparatus is presented, which generates deeply cooled liquid microjets of condensed gases, expelling them via a small aperture into vacuum for use in photoelectron spectroscopy (PES). The functionality of the design is demonstrated by temperatureand concentration-dependent PES measurements of liquid ammonia and solutions of $\mathrm{KI}$ and $\mathrm{NH}_{4} \mathrm{I}$ in liquid ammonia. The experimental setup is not limited to the usage of liquid ammonia solutions solely.
\end{abstract}

Published under license by AIP Publishing. https://doi.org/10.1063/1.5141359

\section{INTRODUCTION}

Since its introduction about 20 years ago, vacuum-based liquid microjet (LJ) technology has evolved as a powerful tool for exploring the electronic structure of the liquid, mostly aqueous solution, by photoelectron spectroscopy (PES). ${ }^{1-13}$ In addition, other measurement techniques (e.g., electrospray ionization in mass spectroscopy, $\mathrm{x}$-ray emission, or Raman scattering) benefit from the development of liquid microjets. ${ }^{13-20}$ LJ-PES has primarily been used to investigate the properties of water and aqueous solutions, starting with the measurement of the full valence photoelectron spectrum from pure water and followed by studies of orbital energies of dissolved molecules and ions. ${ }^{2-5}$ In the last few years, LJs have been enhanced to flatjets allowing further experimental techniques on liquids such as transient soft-xray absorption spectroscopy. ${ }^{21-24}$ Meanwhile, other experimentalists have produced cryogenic liquid microjets of non-polar gases (nitrogen, argon, hydrogen, and methane). ${ }^{25-31}$ However, for PESwhere studying the effects of solvation environments of varying polarity on solutes is of interest-a more versatile apparatus is required.

For our purposes, we aimed at investigating pure liquid ammonia and liquid ammonia with dissolved solutes. Since ammonia is a liquid between $196 \mathrm{~K}$ and $240 \mathrm{~K}$ (its vapor pressure between 0.06 and 1 bar in this temperature regime rises to about 10 bars at room temperature), ${ }^{32}$ an additional technical challenge is the ability to stabilize the setup at variable temperatures with a reliable and fastresponding temperature control system. Furthermore, one of our motivations for conducting a PES study of liquid ammonia was to make direct comparisons with liquid water regarding the effect of bulk hydrogen bonding (H-bonds). The binding energies (BEs) of the valence electrons, particularly those involved in $\mathrm{H}$-bonds, can 
vary considerably depending on the number of $\mathrm{H}$-bonds, which can be expected to change with temperature. ${ }^{18,33,34}$

Perhaps the most prominent example of liquid ammonia solvation chemistry is represented by the colorful solutions of alkali metals in liquid ammonia. As the concentration of alkali metals is increased, the solution color changes from blue to bronze, corresponding to the phase transition from an electrolyte solution of solvated (di-)electrons into a metallic solution. Recent reviews provide the reader with a detailed overview about the history and current status of the spectroscopy of solvated electrons in liquid ammonia. ${ }^{35,36}$ There is no shortage of solvation chemistry unique to ammonia for which photoelectron spectroscopy of the liquid, which requires the use of microjets, would be an immense resource. Photoelectron studies have been conducted for gas as well as solid phases of ammonia by others previously. ${ }^{37,38}$ By developing a device to create a liquid ammonia microjet in vacuum, we recently enabled the respective liquid-phase PES studies of ammonia. ${ }^{39}$ The purpose of the present manuscript is to describe two versions of the experimental setup with focus on temperature control and suitability for various solutes, which is presented in Sec. II. We conclude by showing representative valence PE spectra from the neat solvent at several distinct temperatures as well as from iodide salts dissolved in liquid ammonia.

\section{EXPERIMENTAL DESCRIPTION AND SPECIFICATIONS}

\section{A. Experimental design}

The first design of the apparatus for liquid ammonia (Fig. 1), that we developed, consists of two connected vessels, made of borosilicate glass and stainless steel, respectively. Both vessels are placed in a cold bath of ethanol cooled with liquid nitrogen. Ammonia is condensed in the glass vessel so that the amount of condensate can be observed visually. Then, the ammonia solution is transferred into the stainless steel cylinder.

The cylinder headspace is pressurized with nitrogen gas to 2-5 bars, which presses the solution through a stainless steel micron filter and then via a $1 / 8$ in. OD tubing to a commercially available quartz micronozzle ( $25 \mu \mathrm{m}$ aperture diameter, Microliquid $\mathrm{GmbH}$ ). When pushed through the nozzle, the ammonia solution forms a liquid microjet in the vacuum chamber.
The choice of backing pressure alters the length of the laminar region, the microjet. The $1 / 8$ in. tubing is kept cold by cooled ethanol circulated from the solvent bath using an aquarium pump sitting inside an insulating metal jacket. However, several adapters are needed to connect the tubing with the commercially available nozzle, ${ }^{40}$ and therefore, copper wires were wrapped around this part to support its cooling.

This jacketed feed line was suspended in the vacuum chamber by an XYZ manipulator, allowing the nozzle to be accurately positioned in front of the skimmer of the SOL ${ }^{3}$ PES setup at BESSY II. ${ }^{11}$ This experimental apparatus allowed us to collect the first photoelectron (PE) spectra of liquid ammonia with a run time for the jet of up to $8 \mathrm{~h}$. However, the apparatus had two main shortcomings. First, no accurate temperature control was possible. Second, the jet was not self-starting, as the nozzle frequently clogged almost immediately after initiating. This was rectified by pressing solvents (isopropanol and water) backward into the nozzle using a $1 \mathrm{ml}$ polypropylene syringe. An iterative improvement of this original design was made by extending the active cooling all the way to the nozzle, by embedding the nozzle partially into the metal frame which ameliorated the cooling time of the insulating quartz material. Additionally, a $2 \mu \mathrm{m}$ filter was added approximately $5 \mathrm{~cm}$ before the nozzle. The material of the custom made plastic gasket between the metal tubing and the quartz nozzle is absolutely crucial. The surface of the material must be extreme smooth, otherwise microfibers can shear off easily and clog the nozzle. Therefore, polytetrafluoroethylene (PTFE) is an optimum choice even though it will not be compatible with any alkali-metal solutions in future experiments. After this adaption, it was possible to obtain self-starting liquid ammonia microjets of $20 \mu \mathrm{m}$ diameter. Such an apparatus is still in use at the USC.

Clogging of the nozzle is particularly likely and undesirable in the case of alkali-metal solutions. Therefore, a second apparatus was built for flowing alkali solutions. The most crucial change is the use of larger aperture jet nozzles with a $0.45 \mu \mathrm{m}$ filter immediately preceding the nozzle (Fig. 2). Furthermore, the high-pressure reservoir (1-5 bars) is now placed into the vacuum chamber, mounted on a large XYZ manipulator (CF63, VAB, model: PMM 12). This minimizes the traveled path of the solution when exiting the reservoir and keeps the pyrophoric material safely inside the vacuum system.

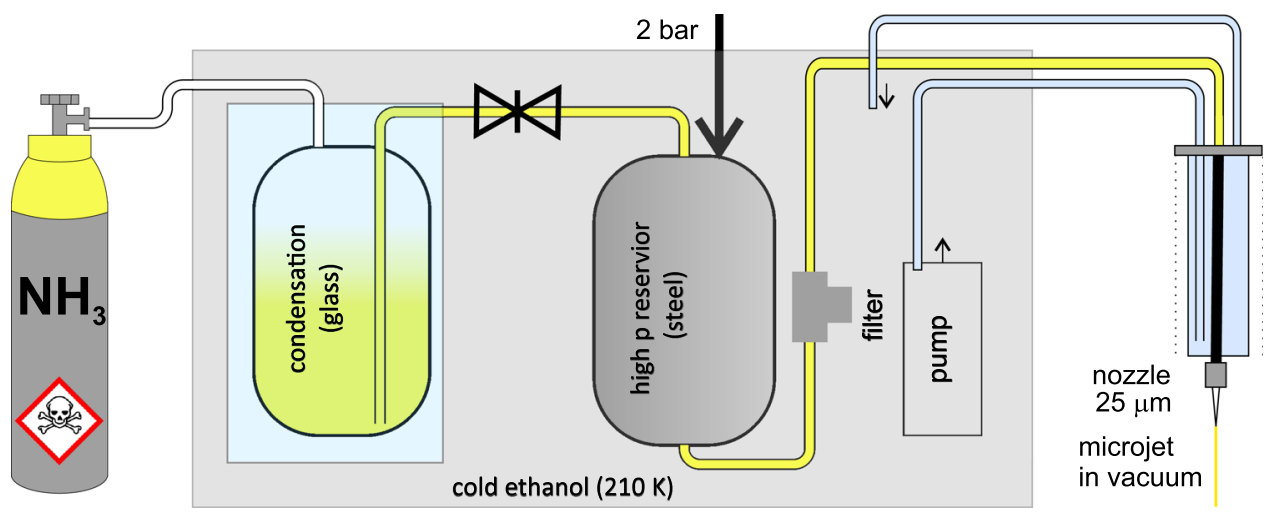

FIG. 1. Sketch of the experimental design as used for first studies with liquid ammonia. ${ }^{39}$ All parts (condensation vessel, filter, and high-pressure reservoir) except the micronozzle were placed outside of the vacuum chamber in a cold bath (ethanol + liquid nitrogen). 


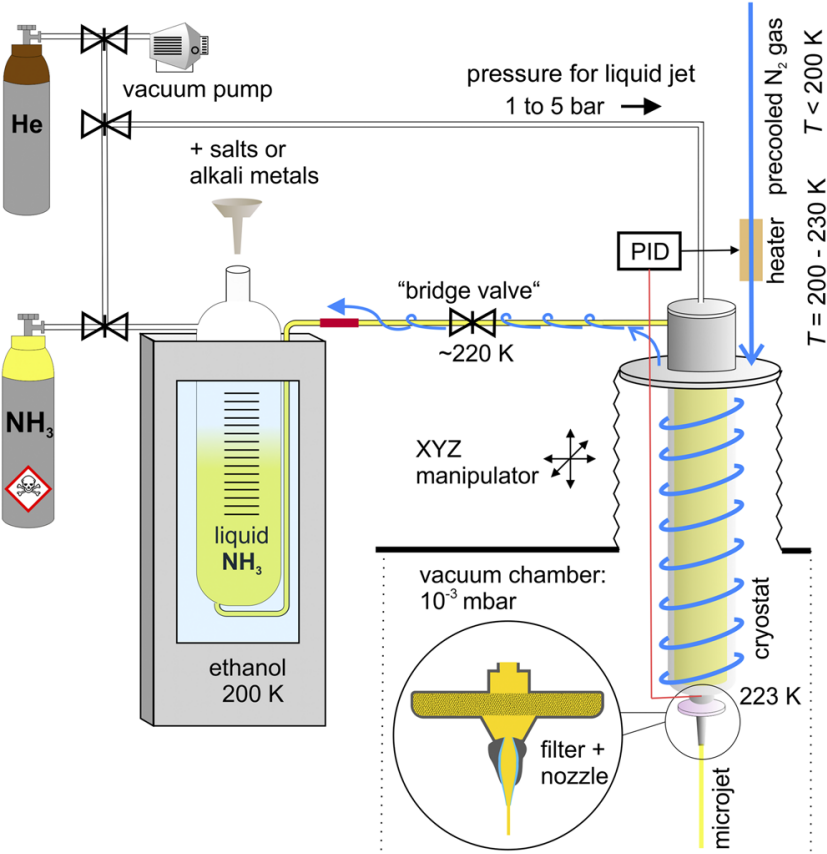

FIG. 2. Sketch of the experimental design with accurate temperature control. Left: Condensation and mixing vessel (glass) in a cold bath (stainless steel with a window). The glass part is connected via a short silicon tube (red) to the high-pressure reservoir (right). The cryostat is built into the vacuum chamber and can be moved by an XYZ manipulator. Inset: Nozzle with a merged filter.

In our previous work on PES of liquid ammonia, ${ }^{39}$ we maintained the temperature of the reservoir roughly within the required temperature regime by filling liquid nitrogen into the ethanol bath once the temperature began to rise (Fig. 1). In order to achieve a much more stable temperature control over time, we implemented a proportional-integral-derivative (PID) feedback system which actively stabilizes the cryostat at a desired set temperature by cooling or heating an adjustable flow of the precooled nitrogen gas.

A borosilicate glass vessel $(400 \mathrm{ml})$, in which the liquid ammonia is condensed by immersion within an insulated homemade container (4 1), is cooled using a bath of ethanol and liquid nitrogen. Circulation of the coolant was facilitated by using an aquarium pump (Eheim, compactON 300) submerged in the cold ethanol, providing a homogeneous temperature $(200-220 \mathrm{~K})$ inside the insulated container. We found a glass vessel useful for collecting condensed ammonia as it allows for visual inspection of the interior of the reservoir. Consequently, for this purpose, the container of the cold bath is fit with a window to see the filling level of the liquid. The concentration of added solutes can, hence, be determined with the aid of volumetric gradations on the glass (Fig. 2).

The condensation vessel has three connections: (i) an inlet for gases (helium and ammonia) which can also be connected to a vacuum pump. The direction of the gas flow is controlled by a $6 \mathrm{~mm}$ ball valve; (ii) an inner joint for the addition of solutes (e.g., salts or alkali metals); and (iii) a glass sidearm, originating at the base of the condensation vessel and running parallel to the walls of the vessel, connects the condensation vessel with a high-pressure reservoir (stainless steel $316 \mathrm{~L}, 300 \mathrm{ml}$ ). Owing to the fragility of metalto-glass seals, a short piece of silicone hose (red) connects the glass sidearm to the sample cylinder, providing flexibility. Both the glassware and sample cylinder can be evacuated independently and kept mutually isolated via a low-temperature bellow-sealed valve (Swagelok, SS-4UW-TF "bridge-valve") separating the two parts of the experimental setup. The purpose of the sample cylinder is that it can be pressurized by a pusher gas via the headspace of the cylinder, which ultimately provides the driving force to expel the solutions through a small aperture (nozzle). A similar approach is used for the characterization of microthrusters. ${ }^{41}$ Helium is preferred as a pusher gas because it does not react at all (e.g., $\mathrm{N}_{2}$ would react with lithium) and because of its low solubility in liquid ammonia compared to argon or nitrogen.

\section{Controlled temperature stabilization of the cryostat}

In principle, the binding energies of solute and solvent electrons are sensitive to the temperature-dependent hydrogen bonding. ${ }^{43}$ In our LJ-PES measurements, we used an active temperature stabilization to assure constant and reproducible results at a given temperature. Figure 4 shows the stability (mean temperature fluctuations), once a set temperature is stabilized of $\pm 0.5 \mathrm{~K}$. We installed a home-built temperature control system where an adjustable flow of cold nitrogen gas is used as the coolant. The gaseous nitrogen flow from a cylinder is transported via $6 \mathrm{~mm}$ copper tubing, guiding the nitrogen gas through a liquid nitrogen-cooled dewar. The copper tubing is then curled into a short helix inside the dewar to maximize the surface area contact with the liquid nitrogen, in order to efficiently cool the gas. The pre-cooled gas is then heated to the temperature range in which ammonia is a liquid using a cartridge heater (LakeShore Cryogenics, model: HTR-50). The control unit (LakeShore Cryogenics, model 350) uses a silicon diode to monitor the temperature measured at the outlet of the cryostat, allowing for adjusting the heating current via feedback from a PID. The cold gas kept at the required temperature is guided through a $3 \mathrm{~mm}$ copper tube wrapped around the stainless steel reservoir (see Fig. 2). The distance between individual loops of the copper tube is approximately $3 \mathrm{~cm}$ to guarantee a high flow rate, which would decrease if more loops were used. Between the stainless steel container and the copper cooling coil, a thin layer of copper tape provides homogeneous cooling. The reservoir is embedded inside an ISO-K 100 flange within the vacuum chamber for safety concerns regarding the reactivity of the solutions (Fig. 2). The outside of the cryostat is covered with alternating layers of polyethylenespacer material and aluminum foil to avoid condensation at the outer walls. The connecting tube between glass and the stainless steel vessel is cooled in the same way just before the solution is transferred from one vessel to the other to keep the ammonia liquid during the transfer.

\section{Nozzle design}

At the inlet of the steel reservoir (Fig. 2), helium gas pressurized to 1-5 bars can be applied to force the cold solution through a filter and a quartz nozzle. The fabricated nozzles have diameters between $50 \mu \mathrm{m}$ and $90 \mu \mathrm{m}$. The syringe filter (pore size: $0.45 \mu \mathrm{m}$, polyethylene, $L L G$ labware) is merged with a quartz nozzle to place the filter directly in front of the nozzle (Fig. 2, inset). The short path 
length between the filter and the nozzle was found to be necessary to reduce clogging of the nozzle.

The nozzles were fabricated by heating a fused silica capillary with $4 \mathrm{~mm}$ outer diameter and an inner diameter of $2 \mathrm{~mm}$ to its softening point and pulling it to a spear point so that the inner diameter is reduced to below $100 \mu \mathrm{m}$ (Fig. 3). This step is repeated at a distance of about $10 \mathrm{~mm}$ on the other side of the original narrowing. Thus, we fabricate a small nozzle with two narrowings on either side of the main body of the capillary. The nozzle is then cut at both sides where the desired inner diameter is found (checked with the microscope, $\pm 5 \mu \mathrm{m}$ ). Obviously, the narrowing at the outlet of the nozzle is needed to form the microjet. We implement the second narrowing (nearest to the filter) to create a sealing surface where the nozzle is merged with the filter. The nozzle is kept in place by melting ( $\approx 400 \mathrm{~K}$ using a small butane torch) and forming a permanent joint after resolidification of the polyethylene. When the reservoir is empty, the filter nozzle unit can be replaced rapidly. This feature is

1.
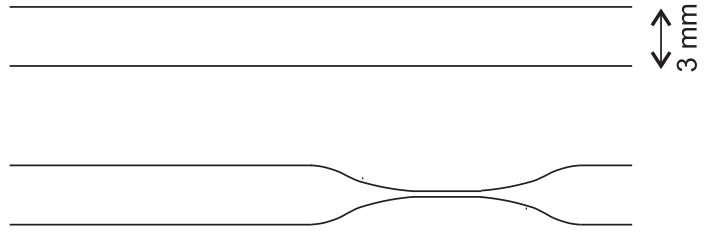

3

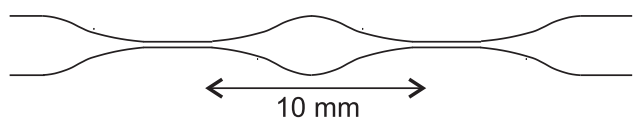

4.

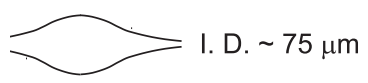

5.

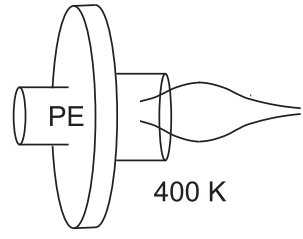

6.

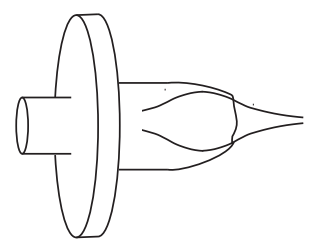

FIG. 3. Custom nozzles are made by taking fused silica tubing $(4 \mathrm{~mm}$ OD, $1 \mathrm{~mm}$ ID): (1) heating and pulling on both sides to create two spear points; (2) another spear point is made $10 \mathrm{~mm}$ away from the first, shown in (3), and the thinnest sections are analyzed under a microscope to determine if the aperture size is $75 \mu \mathrm{m}$ or less. If so, the nozzle is cleaved in that location using a tungsten carbide knife, giving a prototypical nozzle; (4) the nozzle is then inserted into one end of a poly(ethylene) frit filter; and (5) the luer-lock connection of the filter is melted with a butane torch, which creates a seal with the nozzle when it resolidifies, giving the filter-merged nozzle, as shown in (6) and Fig. 2. very favorable, as the lifetime of the filter is limited to a few hours if solutions of alkali metals are used (blocking the filter with small particles). Furthermore, a used filter can be disconnected from the nozzle by melting and replaced by a fresh filter. The nozzles form stable liquid ammonia jets if the critical Reynolds number $R e_{e}$ is not exceeded $\left(R e_{e}=\frac{d v \rho}{\eta}<2300\right)$. Here, we calculate a value of about 400 for $R e_{e}$ with a nozzle diameter $d(\approx 70 \mu \mathrm{m})$, a microjet velocity of $v\left(\approx 4 \mathrm{~m} \mathrm{~s}^{-1}\right.$ corresponding to a flow rate of $\left.1 \mathrm{ml} \mathrm{min}^{-1}\right)$ and the known values of density $\rho\left(700 \mathrm{~kg} \mathrm{~m}^{-3}\right)$, as well as the viscosity $\eta(0.5 \mathrm{mPa} \mathrm{s}) .^{44}$ As the ratios $\rho$ over $\eta$ of water and ammonia are comparable, similar nozzle diameters and jet velocities lead to stable microjets. We note, however, that the laminar criterion should be taken with caution because non-equilibrium conditions are prevalent as the microjet expands into vacuum. The jet decay length $L$ of ammonia microjets is comparable to those of aqueous solutions and can be estimated with the following equation to about $1-3 \mathrm{~mm}:{ }^{45}$ $L \approx 3 v \sqrt{\frac{\rho d^{3}}{\sigma}}$, where $\sigma$ is the surface tension of liquid ammonia. ${ }^{46}$

\section{B. Experimental procedure}

The apparatus without the nozzle is rinsed with water, ethanol, and acetone. After that, a clean nozzle is mounted, and the complete apparatus is dried and purged with helium, at least three times. The absence of oxygen and compounds with dissociable protons is extremely important when dissolving alkali metals. After the apparatus is evacuated, gaseous ammonia (Linde, 6.0) is condensed. As the enthalpy of vaporization of ammonia is large $\left(23 \mathrm{~kJ} \mathrm{~mol}^{-1}\right),{ }^{47}$ liquid nitrogen has to be added to the cold bath every few minutes to ensure a constant rate of condensation. Meanwhile, the volume of liquefied ammonia can be monitored by eye through the window of the cold bath. Once the required amount of liquid ammoniatypically $150 \mathrm{ml}-$ is condensed, it is set under a helium atmosphere (slight over-pressure). We then add the desired solute, e.g., $\mathrm{NH}_{4} \mathrm{I}$, $\mathrm{KI}$, or pure alkali metal, while flushing the condensation vessel with helium at a low flow rate. To speed up the process of dissolution, the solution is set under vacuum for several seconds (ammonia is boiling). The alkali metals were cut and stored under an argon atmosphere before they are added to the liquid ammonia. Mixing of the solution is expedited by setting the solution under vacuum for a few seconds, agitating the solution by the boiling of ammonia. Prior to the transfer of the liquid ammonia solution into the high-pressure reservoir, the connection tube and the bridge-valve are evacuated and then cooled down (see Fig. 2) to prevent the liquid ammonia from boiling. The cold solution is pressed by its own vapor pressure smoothly into the evacuated cryostat when the bridge-valve is opened. Eventually, the remaining solution is transferred by gentle pressurization of the glass vessel with helium. Once the transfer is completed, about 2 bars of helium backing pressure is applied to the high-pressure reservoir to initiate the liquid ammonia microjet. The jet can be started either under atmospheric pressure or under vacuum. A typical experimental procedure consists of the sample preparation, transfer, and thermal equilibration prior to the conduction of measurements, depicted in Fig. 4, where the temperature of the cryostat is shown as a function of time. During the preparation periods, the temperature usually fluctuates rather widely, particularly when the cryostat is evacuated for the first time, due to evaporative cooling from any residual liquid from previous 


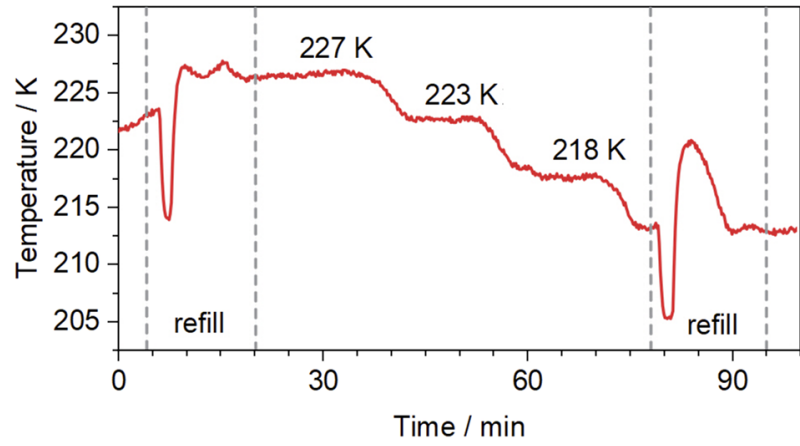

FIG. 4. Temperature evolution of the cryostat during experiments; intervals of refill and thermalization happen in between intervals of conduction of experiments. After sample preparation, the solution is transferred to the stainless steel reservoir of the cryostat where it undergoes an interval of thermalization. The active stabilization equilibrates the system to a set-temperature value. Once the temperature is stabilized, the jet can be started and measurements are performed. The temperature of the cryostat has been stabilized at $227 \mathrm{~K}, 223 \mathrm{~K}$, and $218 \mathrm{~K}$, respectively, to perform the measurements presented in Sec. II B (Fig. 6).

experiments. Second, during filling with a new sample solution, the cryostat heats up upon thermalization with the new sample solution. In the next step, the PID-control unit stabilizes the temperature actively, up (or down) to the desired set-temperature value, before measurements are conducted. The temperature of the solution was stabilized at three different temperatures (e.g., $227 \mathrm{~K}$ to $223 \mathrm{~K}$ and to $218 \mathrm{~K}$; see Fig. 4) in a single run to perform temperature-dependent LJ-PES measurements without changing any other condition during the measurement. The cryostat can, in principle, be stabilized at any temperature within the temperature range where ammonia is liquid. However, at temperatures higher than $230 \mathrm{~K}$, the vapor pressure of ammonia increases as well, leading to a decrease in the liquid-phase PES signal due to increasing electron scattering. On the other hand, at temperatures below $210 \mathrm{~K}$, the liquid jet tends to freeze immediately at the nozzle since the jet evaporatively cools when injected into vacuum. Whereas the vacuum pumps transfer a fraction of the evaporated ammonia to the exhaust, the other fraction of the ammonia condenses on two cold traps. After a set of experiments, the cold traps have to be removed and transported in a closed system to a hood, where the ammonia can evaporate safely.

\section{PHOTOELECTRON SPECTROSCOPY}

In order to perform $\mathrm{x}$-ray photoelectron spectroscopy measurements from pure liquid ammonia as well as from liquid ammonia salt solutions, the above described experimental kits were mounted on the top of the SOL ${ }^{3} \mathrm{PES}$ experimental setup ${ }^{11}$ at the synchrotron radiation facility BESSY II. A turbomolecular drag pump (Pfeiffer Vacuum TMH 1601) in combination with two cold traps maintained the pressure in the main chamber at the order of $10^{-3}$ mbar. All measurements are performed at the beamline UE52-SGM. ${ }^{48}$ We first present measurements with the setup shown in Fig. 1 from ions in liquid ammonia. The experimentally obtained BEs are compared to ions in aqueous solutions. Second, we demonstrate the performance of the cryostat's temperature control with the 2nd-generation setup (Fig. 2).

\section{A. Photoelectron spectra of dissolved salts in liquid ammonia}

Ammonia is a good solvent (similar to water) for many polar solutes, including salts. As an example, we present in Fig. 5 the liquid-jet valence $\mathrm{PE}$ spectra from $0.5 \mathrm{M} \mathrm{NH}_{4} \mathrm{I}$ as well as $0.5 \mathrm{M} \mathrm{KI}$ dissolved in liquid ammonia. Here, we used the experimental apparatus described in Fig. 1, and the pressure in the main chamber was $4-7 \cdot 10^{-3}$ mbar. Spectra from $\mathrm{NH}_{4} \mathrm{I}$ solutions were measured with a photon energy of $640 \mathrm{eV}$. The KI solution spectra were measured with $640 \mathrm{eV}$ and $265 \mathrm{eV}$, respectively. Spectra are displayed such that the $3 \mathrm{a}_{1}$ liquid peak is at $9.09 \mathrm{eV} .^{39}$ In addition, the intensities of the $3 a_{1}$ liquid peaks are displayed to yield the same peak height.

The signals near $14-18 \mathrm{eV}$ and $8-12 \mathrm{eV}$ are assigned to the $1 \mathrm{e}$ and $3 a_{1}$ orbitals of ammonia (gas and liquid), respectively. Whereas

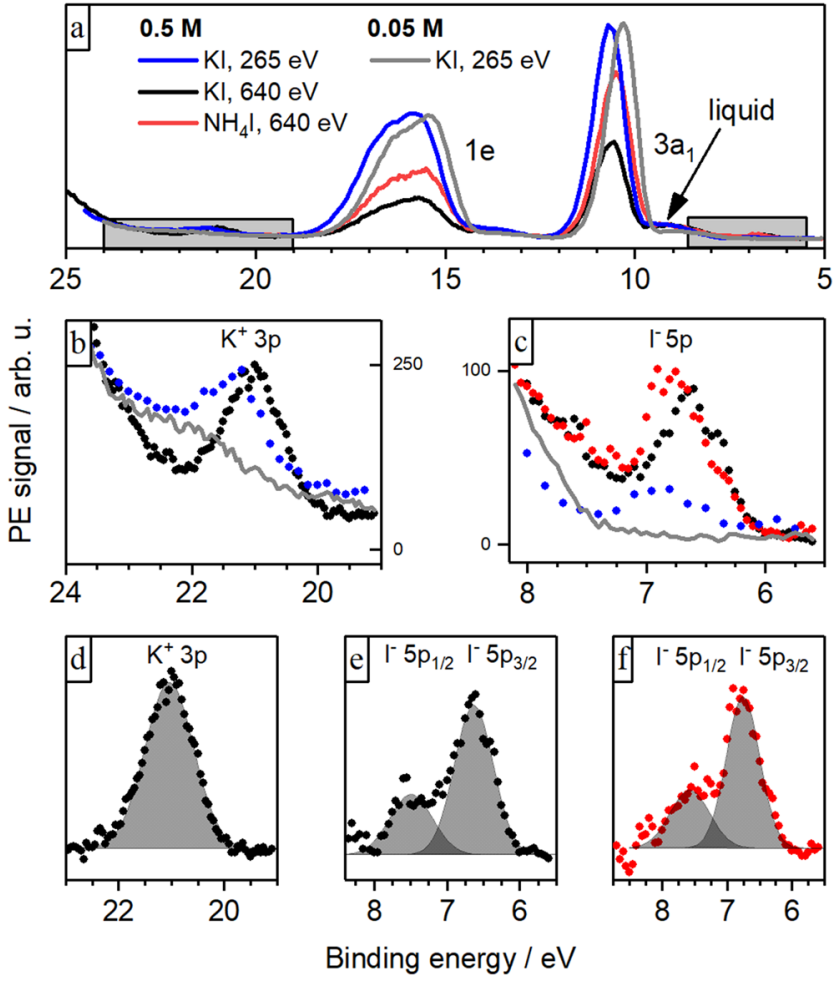

FIG. 5. (a) Photoelectron spectra of $0.5 \mathrm{M} \mathrm{KI}$ (black) and $0.5 \mathrm{M} \mathrm{NH}_{4} \mathrm{I}$ (red) liquid ammonia solutions-both measured at a photon energy of $640 \mathrm{eV}$-and a $0.5 \mathrm{M}$ $\mathrm{KI}$ solution (blue) and a $0.05 \mathrm{M} \mathrm{KI}$ solution (gray), both measured at $265 \mathrm{eV}$. All measurements are calibrated and normalized at the $3 \mathrm{a}_{1}$ peak of the liquid phase of ammonia $(9.09 \mathrm{eV})$. All spectra are measured at a detection angle parallel to the light polarization. (b) and (c) Magnification of the highlighted areas (in a) between $5.5 \mathrm{eV}$ and $8.5 \mathrm{eV}\left(I^{-} 5 p\right)$ and between $19 \mathrm{eV}$ and $24 \mathrm{eV}\left(\mathrm{K}^{+} 3 \mathrm{p}\right)$. (d) $-(\mathrm{f})$ : Gaussian fits of the $\mathrm{K}^{+} 3 p$ and $\mathrm{I}^{-} 5 \mathrm{p}$ peaks after subtraction of the ammonia signals. These data have been measured with the design of the experimental setup, described in Fig. 1. 
TABLE I. BEs and FWHM values of $\mathrm{K}^{+}$and $\mathrm{I}^{-}$in liquid ammonia. The data of $\mathrm{K}^{+}$and $\mathrm{I}^{-}$in the aqueous solution are shown for comparison.

\begin{tabular}{|c|c|c|c|c|c|c|c|c|c|c|}
\hline \multirow[b]{2}{*}{ Solution } & \multicolumn{2}{|c|}{$\mathrm{K}^{+} 3 \mathrm{p}$} & \multicolumn{2}{|c|}{$\mathrm{I}^{-} 5 \mathrm{p}_{1 / 2}$} & \multicolumn{2}{|c|}{$\mathrm{I}^{-} 5 \mathrm{p}_{3 / 2}$} & \multicolumn{2}{|c|}{$\Delta_{g-l}$} & \multicolumn{2}{|c|}{$R_{e f f}$} \\
\hline & Center & FWHM & Center & FWHM & Center & FWHM & $\mathrm{K}^{+}$ & $\mathrm{I}^{-}$ & $\mathrm{K}^{+}$ & $\mathrm{I}^{-}$ \\
\hline $0.5 \mathrm{M} \mathrm{KI}$ in $\mathrm{NH}_{3}$ & 21.0 & 1.1 & 7.5 & 0.7 & 6.6 & 0.63 & -10.52 & 3.99 & $1.97(1.78)$ & $1.73(2.07)$ \\
\hline $0.5 \mathrm{M} \mathrm{NH}_{4} \mathrm{I}$ in $\mathrm{NH}_{3}$ & & & 7.5 & 0.7 & 6.8 & 0.61 & & 4.19 & & $1.70(2.07)$ \\
\hline $0.5 \mathrm{M} \mathrm{KI}$ in $\mathrm{H}_{2} \mathrm{O}$ & $22.2^{\mathrm{a}}$ & $1.4^{\mathrm{a}}$ & $8.8^{\mathrm{a}} ; 8.9^{\mathrm{b}}$ & 1.1 & $7.7^{\mathrm{a}} ; 8.03^{\mathrm{b}}$ & $0.8^{\mathrm{a}}$ & -9.42 & 5.15 & $2.27(2.05)$ & $1.38(1.60)$ \\
\hline
\end{tabular}

${ }^{\mathrm{a}}$ From Ref. 51.

${ }^{\mathrm{b}}$ From Ref. 52. All values are given in electronvolts, except for $R_{e f f}$, which are given in angstroms and calculated with the Born equation. The values given in brackets are calculated with the estimated onset energies instead of the peak centers. Note that the accuracy of the BEs of the solvents ions depends on the accuracy of the calibrated BEs of liquid ammonia. ${ }^{3}$

the most prominent peaks result from ionizing the gas phase (due to a high vapor pressure, $\approx 400 \mathrm{mbar}$ ), the liquid signal is reflected by the smaller peaks at lower BEs $(14.3 \mathrm{eV}$ and $9.09 \mathrm{eV}) .{ }^{39}$ Due to the high concentration of salt, the gas-phase peaks are at a slightly higher $\mathrm{BE}$ compared to a solution with lower concentration (gray line, $50 \mathrm{mM}$ KI solution). This is a known effect in aqueous solution jets and reflects the change in the electric field arising from the changes in the liquid solution surface potential.

In addition to the signals of ammonia, we observe electronic signatures near $7 \mathrm{eV}$ and near $21 \mathrm{eV}$, which are assigned to the $\mathrm{I}^{-}$ and $\mathrm{K}^{+}$solute ions, respectively. Signals from the ammonium cation could not be observed, presumably because it overlaps with the gas and liquid ammonia PE signals between 9 and $12 \mathrm{eV}$. It is notable that the measurement with a $265 \mathrm{eV}$ photon energy shows a less intense peak $[\approx 50 \%$, Fig. $5(\mathrm{c})]$ for $\mathrm{I}^{-}$while exhibiting a similar peak height for the $\mathrm{K}^{+}$[Fig. 5(b)]. In a first approximation, this can be explained with different cross sections of the ions. The ratios of peak heights of $\mathrm{K} 3 \mathrm{p}$ to I $5 \mathrm{p}$ at $265 \mathrm{eV}$ and $640 \mathrm{eV}$ (7.5 and 2.8) roughly reflect the ratios of the cross sections at the different photon energies (6.3 and 2.8), respectively. ${ }^{50}$

For a quantitative analysis of the $\mathrm{K}^{+}$and $\mathrm{I}^{-}$spectral contributions, we present peak fits for $\mathrm{KI}$ and $\mathrm{NH}_{4} \mathrm{I}$ solutions in Figs. 5(e) and (f), respectively. The results are summarized in Table I, along with binding energy shifts between the gas phase and the liquid phase, $\Delta_{g-l}$, and corresponding binding energies in aqueous solutions. ${ }^{51,52}$ Surprisingly, $\Delta_{g-l}$, which would be expected to be greater for water for both ions, is larger for $\mathrm{K}^{+}$in the less polar ammonia solution.

A convenient approach to calculate the BEs of dissolved ions in the solution and compare them to the measured values is based on the Born equation, which describes the screening contribution of the liquid to the dissolved ions as a function of relative permittivity of the solvent $\varepsilon$ and ionic radius of the solute $R_{\text {eff. }}{ }^{51,53}$ Here, we assume a homogeneous relative permittivity of the solvent. This may be questioned, as the mobility of the dipole orientations (dielectric saturation) and the excess volume of the solute (electrostriction) are decreased due to the electrostatic interactions between the solute and nearest solvent molecules. ${ }^{54-56}$ The Born Equation is not predictive if we employ the crystallographic radii for the ions-for example, it would predict a larger $\Delta_{g-l}$ for water than ammonia, which is not observed for $\mathrm{K}^{+}$. Instead, we can explore what values of $R_{\text {eff }}$ are required for water and ammonia to reproduce the experimental binding energies. ${ }^{57}$ The results are shown in Table I. This approach suggests that the $R_{\text {eff }}$ of $\mathrm{K}^{+}$shrinks by $\approx 0.3 \AA$, whereas the $R_{\text {eff }}$ of $I^{-}$ expands by $\approx 0.3 \AA$ if the solvent is switched from water to ammonia. As the Born equation predicts the onset energies and not the vertical peak center, ${ }^{58}$ we have also calculated $R_{\text {eff }}$ with the estimated onset values, and the qualitative picture does not change. More predictive approaches to analyzing the solvation shift to the electron binding energy include quantum mechanics/molecular mechanics (QM/MM) and $a b$ initio molecular dynamics (AIMD), which have been successfully applied for aqueous ions. ${ }^{51,59}$

\section{B. Liquid ammonia PES at different temperatures}

To characterize the performance of temperature control of the experimental setup, photoelectron spectra of a liquid ammonia solution were measured. We added $50 \mathrm{mM} \mathrm{KBr}$ to eliminate effects arising from the streaming potential, ${ }^{52}$ while the temperature of the cryostat was stabilized at $227 \mathrm{~K}, 223 \mathrm{~K}$, and $218 \mathrm{~K}$. The jet flow

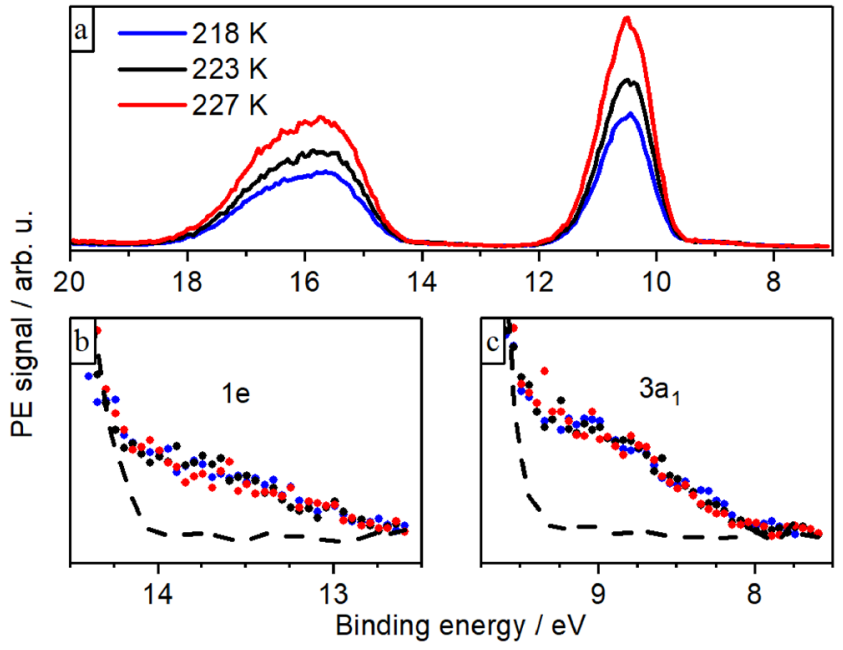

FIG. 6. Valence PE spectra of liquid ammonia solutions $(50 \mathrm{mM} \mathrm{KBr})$ are measured at three different temperatures: $218 \mathrm{~K}$ (blue), $223 \mathrm{~K}$ (black), and $227 \mathrm{~K}$ (red). The spectra are measured for 8 min ( 8 sweeps) using a photon energy of $265 \mathrm{eV}$, normalized and calibrated to the fitted $3 a_{1}$ liquid-phase peak at $9.09 \mathrm{eV}$ (a). Magnification of the liquid-phase signal of the $3 a_{1}$ and $1 e$ liquid peaks does not show any shift or broadening [(b) and (c)]. The dashed line represents the gas-phase spectra. Spectra were recorded with the microjet design shown in Fig. 2. 
rate was $0.6 \mathrm{ml} \mathrm{min}^{-1}$, and the pressure in the main chamber was $5-8 \cdot 10^{-3}$ mbar. We used the apparatus shown in Fig. 2. Results are presented in Fig. 6.

The observed $70 \%$ increase in the gas-peak signal (near $16 \mathrm{eV}$ and $10.5 \mathrm{eV}$ ) upon raising the temperature from $218 \mathrm{~K}$ to $227 \mathrm{~K}$ well reflects the change in vapor pressures [ $300 \mathrm{mbars}$ at $218 \mathrm{~K}$ and 510 mbars at $227 \mathrm{~K}$, increase of $70 \%$, Fig. 6(a)]. ${ }^{32}$ This demonstrates the accurate temperature control of the microjet and a preservation of the temperature difference even after considering evaporative cooling as the jet flows into vacuum. Within the measured temperature range, we do not observe any additional gas-liquid shift or a change in the peak shape of the liquid-phase signals [Figs. 6(b) and 6(c)]. Nevertheless, as accurate temperature control is now available, changes in the hydrogen network on the solvent orbital energies might be detected for other liquids, measured over a broader temperature range or if smaller nozzles are used to increase the ratio of the liquid to the gas signal for volatile solvents such as ammonia. Under extreme non-equilibrium conditions (IR laser heating, $400 \mathrm{~K}), \mathrm{H}$-bonding dynamics in water and methanol has been tracked by time resolved PES. ${ }^{60,61}$

\section{SUMMARY}

In summary, deeply cooled microjets of solutions of liquid ammonia can be investigated spectroscopically by using the above described apparatus under temperature controlled conditions. The performance of our experimental designs, in conjunction with PES, is demonstrated by two examples. First, valence binding energies of $\mathrm{I}^{-}$and $\mathrm{K}^{+}$in liquid ammonia are measured, and the results are compared to aqueous solutions. Second, a temperature-dependent study shows good agreement with the expected increase in the gas to liquid ratio in the $\mathrm{x}$-ray photoelectron spectrum as the vapor pressure increases with temperature. Currently, studies of solvated electrons in liquid ammonia are our immediate goal, and the apparatus has been designed with this in mind. Finally, we note that the present technique should allow spectroscopic probing of deeply cooled liquid microjets of other solvents as well. The temperature range of this device is not limited to the current values of 215-240 K. Such liquids may include complex amines, hydrofluorocarbons, and hydrocarbons. Finally, the experimental design described here could be adapted to create flat refrigerated liquid jets. ${ }^{21-24}$

\section{ACKNOWLEDGMENTS}

The authors thank the glass and mechanical workshops of the FHI in Berlin, the IOCB in Prague, the USC as well as the HZB staff prior to and during the beamtime for their assistance at BESSY II. The authors appreciate helpful comments from Dr. Manfred Faubel. P.E.M. acknowledges support from the viewers of his YouTube science channel. S.E.B. and R.S.M. are supported by the U.S. National Science Foundation (CHE-1665532). R.S.M. received additional funds from the States of Jersey Postgraduate Bursary. R.S. and B.W. gratefully acknowledge financial support from the German Research Foundation (DFG) within the Collaborative Research Center 1109. R.S. also acknowledges an Emmy Noether Young Investigator stipend through the DFG (project SE 2253/3-1). T.B. was supported by the Czech Ministry of Education and the EU (Grant No. CZ.02.2.69/0.0/0.0/16_027/0008477). P.J. thanks the European Regional Development Fund (Project ChemBioDrug No. CZ.02.1.01/0.0/0.0/16_019/0000729).

\section{REFERENCES}

${ }^{1}$ M. Faubel, B. Steiner, and J. P. Toennies, J. Chem. Phys. 106, 9013 (1997).

${ }^{2}$ B. Winter, R. Weber, W. Widdra, M. Dittmar, M. Faubel, and I. V. Hertel, J. Phys. Chem. A 108, 2625 (2004).

${ }^{3}$ B. Winter and M. Faubel, Chem. Rev. 106, 1176 (2006).

${ }^{4}$ B. Winter, M. Faubel, I. V. Hertel, C. Pettenkofer, S. E. Bradforth, B. Jagoda-Cwiklik, L. Cwiklik, and P. Jungwirth, J. Am. Chem. Soc. 128, 3864 (2006).

${ }^{5}$ M. N. Pohl, E. Muchová, R. Seidel, H. Ali, Š. Sršeň, I. Wilkinson, B. Winter, and P. Slavíček, Chem. Sci. 10, 848 (2019).

${ }^{6}$ Y. Tang, H. Shen, K. Sekiguchi, N. Kurahashi, T. Mizuno, Y.-I. Suzuki, and T. Suzuki, Phys. Chem. Chem. Phys. 12, 3653 (2010).

${ }^{7}$ R. Seidel, S. Thürmer, and B. Winter, J. Phys. Chem. Lett. 2, 633 (2011).

${ }^{8}$ A. T. Shreve, M. H. Elkins, and D. M. Neumark, Chem. Sci. 4, 1633 (2013).

${ }^{9}$ M. H. Elkins, H. L. Williams, A. T. Shreve, and D. M. Neumark, Science 342, 1496 (2013).

${ }^{10}$ R. Seidel, B. Winter, and S. E. Bradforth, Annu. Rev. Phys. Chem. 67, 283 (2016)

${ }^{11}$ R. Seidel, M. N. Pohl, H. Ali, B. Winter, and E. F. Aziz, Rev. Sci. Instrum. 88, 073107 (2017).

${ }^{12}$ H. L. Williams, B. A. Erickson, and D. M. Neumark, J. Chem. Phys. 148, 194303 (2018).

${ }^{13}$ J. A. Faust and G. M. Nathanson, Chem. Soc. Rev. 45, 3609 (2016).

${ }^{14}$ L. Chen, Z. Chen, Z. Li, J. Hu, and S. X. Tian, Rev. Sci. Instrum. 89, 103102 (2018).

${ }^{15}$ M. Schlenk, E. Hofmann, S. Seibt, S. Rosenfeldt, L. Schrack, M. Drechsler, A. Rothkirch, W. Ohm, J. Breu, S. Gekle, and S. Förster, Langmuir 34, 4843 (2018).

${ }^{16}$ I. Jordan, M. Huppert, M. A. Brown, J. A. van Bokhoven, and H. J. Wörner, Rev. Sci. Instrum. 86, 123905 (2015).

${ }^{17}$ M. Kühnel, J. M. Fernández, G. Tejeda, A. Kalinin, S. Montero, and R. E. Grisenti, Phys. Rev. Lett. 106, 245301 (2011).

${ }^{18}$ P. Wernet, D. Nordlund, U. Bergmann, M. Cavalleri, M. Odelius, H. Ogasawara, L. Näslund, T. K. Hirsch, L. Ojamäe, P. Glatzel, L. G. M. Pettersson, and A. Nilsson, Science 304, 995 (2004).

${ }^{19}$ J. D. Smith, C. D. Cappa, K. R. Wilson, B. M. Messer, R. C. Cohen, and R. J. Saykally, Science 306, 851 (2004).

${ }^{20}$ M. Ryazanov and D. J. Nesbitt, J. Chem. Phys. 150, 044201 (2019).

${ }^{21}$ M. Ekimova, W. Quevedo, M. Faubel, P. Wernet, and E. T. J. Nibbering, Struct. Dyn. 2, 054301 (2015).

${ }^{22}$ L. Obst, S. Göde, M. Rehwald, F.-E. Brack, J. Branco, S. Bock, M. Bussmann, T. E. Cowan, C. B. Curry, F. Fiuza, M. Gauthier, R. Gebhardt, U. Helbig, A. Huebl, U. Hübner, A. Irman, L. Kazak, J. B. Kim, T. Kluge, S. Kraft, M. Loeser, J. Metzkes, R. Mishra, C. Rödel, H.-P. Schlenvoigt, M. Siebold, J. Tiggesbäumker, S. Wolter, T. Ziegler, U. Schramm, S. H. Glenzer, and K. Zeil, Sci. Rep. 7, 10428 (2017).

${ }^{23}$ B. Ha, D. P. DePonte, and J. G. Santiago, Phys. Rev. Fluids 3, 114202 (2018).

${ }^{24}$ J. D. Koralek, J. B. Kim, P. Brǔža, C. B. Curry, Z. Chen, H. A. Bechtel, A. A. Cordones, P. Sperling, S. Toleikis, J. F. Kern, S. P. Moeller, S. H. Glenzer, and D. P. DePonte, Nat. Commun. 9, 2860 (2018).

${ }^{25}$ L. Malmqvist, L. Rymell, M. Berglund, and H. M. Hertz, Rev. Sci. Instrum. 67, 4150 (1996).

${ }^{26}$ M. Berglund, L. Rymell, H. M. Hertz, and T. Wilhein, Rev. Sci. Instrum. 69, 2361 (1998).

${ }^{27}$ P. A. C. Jansson, B. A. M. Hansson, O. Hemberg, M. Otendal, A. Holmberg, J. de Groot, and H. M. Hertz, Appl. Phys. Lett. 84, 2256 (2004).

${ }^{28}$ P. A. C. Jansson, U. Vogt, and H. M. Hertz, Rev. Sci. Instrum. 76, 043503 (2005).

${ }^{29}$ M. Wieland, T. Wilhein, M. Faubel, C. Ellert, M. Schmidt, and O. Sublemontier, Appl. Phys. B 72, 591 (2001).

${ }^{30}$ L. B. Fletcher, U. Zastrau, E. Galtier, E. J. Gamboa, S. Goede, W. Schumaker, A. Ravasio, M. Gauthier, M. J. MacDonald, Z. Chen, E. Granados, H. J. Lee, A. Fry, J. B. Kim, C. Roedel, R. Mishra, A. Pelka, D. Kraus, B. Barbrel, T. Döppner, and S. H. Glenzer, Rev. Sci. Instrum. 87, 11E524 (2016). 
${ }^{31}$ J. B. Kim, C. Schoenwaelder, and S. H. Glenzer, Rev. Sci. Instrum. 89, 10K105 (2018).

${ }^{32} \mathrm{~J}$. Speight, Lange's Handbook of Chemistry, 17th ed. (McGraw Hill Book Co., 2016).

${ }^{33}$ J. A. Sellberg, S. Kaya, V. H. Segtnan, C. Chen, T. Tyliszczak, H. Ogasawara, D. Nordlund, L. G. M. Pettersson, and A. Nilsson, J. Chem. Phys. 141, 034507 (2014).

${ }^{34}$ T. Fransson, Y. Harada, N. Kosugi, N. A. Besley, B. Winter, J. J. Rehr, L. G. M. Pettersson, and A. Nilsson, Chem. Rev. 116, 7551 (2016).

${ }^{35}$ E. Zurek, P. P. Edwards, and R. Hoffmann, Angew. Chem., Int. Ed. 48, 8198 (2009).

${ }^{36}$ P. Vöhringer, Annu. Rev. Phys. Chem. 66, 97 (2015).

${ }^{37}$ A. Lindblad, H. Bergersen, W. Pokapanich, M. Tchaplyguine, G. Öhrwall, and O. Björneholm, Phys. Chem. Chem. Phys. 11, 1758 (2009).

${ }^{38}$ D. Edvardsson, P. Baltzer, L. Karlsson, B. Wannberg, D. M. P. Holland, D. A. Shaw, and E. E. Rennie, J. Phys. B: At., Mol. Opt. Phys. 32, 2583 (1999).

${ }^{39}$ T. Buttersack, P. E. Mason, R. S. McMullen, T. Martinek, K. Brezina, D. Hein, H. Ali, C. Kolbeck, C. Schewe, S. Malerz, B. Winter, R. Seidel, O. Marsalek, P. Jungwirth, and S. E. Bradforth, J. Am. Chem. Soc. 141, 1838 (2019).

${ }^{40}$ J. Braun, P. K. Day, J. P. Toennies, G. Witte, and E. Neher, Rev. Sci. Instrum. 68, 3001 (1997).

${ }^{41}$ J. Blandino, M. McDevitt, J. Mueller, D. Bame, and A. Green, J. Propul. Power 22, 677 (2006).

${ }^{42}$ D. R. Lide, CRC Handbook Chemistry and Physics, 85th ed. (CRC Press, 2004).

${ }^{43}$ R. C. Dougherty, J. Chem. Phys. 109, 7372 (1998).

${ }^{44}$ G. Guevara-Carrion, J. Vrabec, and H. Hasse, Int. J. Thermophys. 33, 449 (2012).
${ }^{45}$ M. Faubel, in Photoionization and Photodetachment (World Scientific, 2000), pp. 634-690.

${ }^{46}$ R. A. Stairs and M. J. Sienko, J. Am. Chem. Soc. 78, 920 (1956).

${ }^{47}$ N. S. Osborne and M. S. van Dusen, J. Am. Chem. Soc. 40, 14 (1918).

${ }^{48}$ P. S. Miedema, W. Quevedo, and M. Fondell, J. Large-Scale Res. Facil. 2, A70 (2016).

${ }^{49}$ N. Preissler, F. Buchner, T. Schultz, and A. Lübcke, J. Phys. Chem. B 117, 2422 (2013).

${ }^{50} \mathrm{~J} .-\mathrm{J}$. Yeh, Atomic Calculation of Photoionization Cross Sections and Asymmetry Parameters (Gordon and Breach, Langhorne, PA, 1993).

${ }^{51}$ B. Winter, R. Weber, I. V. Hertel, M. Faubel, P. Jungwirth, E. C. Brown, and S. E. Bradforth, J. Am. Chem. Soc. 127, 7203 (2005).

${ }^{52}$ N. Kurahashi, S. Karashima, Y. Tang, T. Horio, B. Abulimiti, Y.-I. Suzuki, Y. Ogi, M. Oura, and T. Suzuki, J. Chem. Phys. 140, 174506 (2014).

${ }^{53}$ M. Born, Z. Phys. 1, 45 (1920).

${ }^{54}$ T. Abe, J. Phys. Chem. 90, 713 (1986).

${ }^{55}$ C. S. Babu and C. Lim, J. Chem. Phys. 114, 889 (2001).

${ }^{56}$ P. Koehl, H. Orland, and M. Delarue, J. Phys. Chem. B 113, 5694 (2009).

${ }^{57}$ Y. Marcus, Chem. Rev. 88, 1475 (1988).

${ }^{58}$ B. Jagoda-Cwiklik, P. Slavícček, L. Cwiklik, D. Nolting, B. Winter, and P. Jungwirth, J. Phys. Chem. A 112, 3499 (2008).

${ }^{59}$ A. P. Gaiduk, M. Govoni, R. Seidel, J. H. Skone, B. Winter, and G. Galli, J. Am. Chem. Soc. 138, 6912 (2016).

${ }^{60}$ O. Link, E. Lugovoy, K. Siefermann, Y. Liu, M. Faubel, and B. Abel, Appl. Phys. A 96, 117 (2009).

${ }^{61}$ E. Vöhringer-Martinez, O. Link, E. Lugovoy, K. R. Siefermann, F. Wiederschein, H. Grubmüller, and B. Abel, Phys. Chem. Chem. Phys. 16, 19365 (2014). 